\title{
Assessment of Preoperative Liver Function for Surgical Decision Making in Patients with Hepatocellular Carcinoma
}

\author{
Takashi Kokudo $^{a} \quad K^{2}$ iyoshi Hasegawa ${ }^{a}$ Chikara Shirata $^{a}$ \\ Meguri Tanimoto $^{a}$ Takeaki Ishizawa $^{a}$ Junichi Kaneko ${ }^{a}$ \\ Nobuhisa Akamatsu ${ }^{a}$ Junichi Arita ${ }^{a}$ Nicolas Demartines $^{b}$ Emilie Uldry ${ }^{b}$ \\ Norihiro Kokudoc ${ }^{c}$ Nermin Halkic ${ }^{b}$ \\ ${ }^{a}$ Hepato-Biliary-Pancreatic Surgery Division and Artificial Organ and Transplantation \\ Division, Department of Surgery, Graduate School of Medicine, The University of Tokyo, \\ Tokyo, Japan; ${ }^{b}$ Department of Visceral Surgery, University Hospital Centre Hospitalier

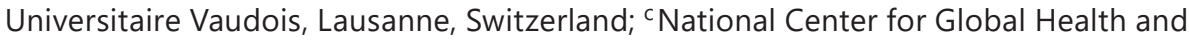 \\ Medicine, Tokyo, Japan
}

\author{
Keywords \\ Hepatocellular carcinoma · Portal hypertension · Indocyanine green
}

\begin{abstract}
Background: Most patients with hepatocellular carcinoma (HCC) have underlying liver disease and a preoperative liver function evaluation is important to avoid postoperative liver failure and death. In Western guidelines, portal hypertension $(\mathrm{PH})$ is listed as a contraindication for liver resection. On the other hand, the indocyanine green retention rate at $15 \mathrm{~min}$ (ICG R15) has been widely used in Asian countries for surgical decision making. However, these criteria are based on reports published in the 20th century that included only a small number of patients and were developed empirically. Summary: The number of published case series concerning liver resection in HCC patients with PH has been rapidly increasing since 2011, indicating that liver resection in $\mathrm{HCC}$ patients with $\mathrm{PH}$ is now routinely performed in specialized centers worldwide. Although PH certainly has an impact and should be considered as a contraindication for major liver resection, it is no longer considered to be a contraindication for minor liver resection, especially laparoscopic liver resection. In addition, new biomarkers and imaging tools to assess preoperative liver function have been extensively reported. The combination of these new factors to well-known risk factors, such as PH and ICG R15, might strengthen the ability to stratify the risk of postoperative liver failure. Key Messages: The present review covers recent topics regarding the assessment of preoperative liver function for surgical decision making in patients with HCC.




\section{Liver Cancer}

\section{Introduction}

Most patients with hepatocellular carcinoma (HCC) have underlying liver disease, which has a significant impact on postoperative short-term and long-term outcomes [1]. A preoperative liver function evaluation is important to avoid postoperative liver failure, which is defined by an increased prothrombin time-international normalized ratio and concomitant hyperbilirubinemia on or after postoperative day 5, as proposed by the International Study Group of Liver Surgery (ISGLS) [2]. In the American Association for the Study of the Liver Disease/Barcelona Clinic for Liver Cancer (AASLD/BCLC) Staging System and treatment guidelines, portal hypertension (PH) is listed as a contraindication for liver resection $[3,4]$. On the other hand, the indocyanine green retention rate at 15 min (ICG R15) has been widely used in Asian countries for surgical decision making, and the treatment guidelines recommend the use of the ICG test to evaluate preoperative liver function $[5,6]$. However, these criteria are based on reports published in the 20th century that included only a small number of patients and were developed empirically [7, 8].

As a result of recent advances in surgical techniques and perioperative management, liver resection has become safer and mortality rates have decreased [9-12]. Aggressive surgical resection and repeated resection for HCC has been reported to offer a survival benefit [13-17]. In addition, three-dimensional (3D) volumetric analysis has significantly contributed to precise surgical planning and safe hepatectomy [18-20]. These changes and the development of surgical strategies for HCC patients suggest a need for more sensitive and accurate criteria than the presence of PH or the ICG R15 value alone. To date, however, no preoperative liver function evaluation criteria for surgical decision making in patients with HCC have been established worldwide.

The present review covers recent topics regarding preoperative liver function assessment for HCC patients in terms of surgical decision making.

\section{Child-Pugh Classification}

In 1964, Child and Turcotte, two surgeons who performed portocaval shunt surgery, initially developed a classification to predict postoperative mortality [21]. Afterwards, the Child-Pugh score was first used to predict short-term and long-term outcomes in a report that was based on the data of only 38 patients who had undergone transection of the esophagus for bleeding varices [22]. Thus, neither the Child-Turcotte classification nor the Child-Pugh score were developed to predict patient outcome after liver resection. In fact, at least three factors (encephalopathy, serum bilirubin, and ascites) are normal in most surgical candidates for liver resection. Nevertheless, the Child-Pugh classification continues to be widely used in surgical decision making for liver resection. This situation is based on the fact that Child-Pugh B patients have a significantly poorer prognosis than Child-Pugh A patients with regard to both short-term and long-term outcomes $[23,24]$. In most Western centers, liver resection is limited to Child-Pugh A patients [25]. Although a Child-Pugh B classification may not be an absolute contraindication for liver resection, major liver resection should be avoided in these patients, and liver transplantation should be considered whenever appropriate [24].

Johnson et al. [26] proposed a new evidence-based objective liver function grading system based only on the serum albumin and bilirubin levels, the so-called ALBI grading system. In general, ALBI grades 1, 2, and 3 correspond to Child-Pugh A, B, and C, respectively. Recently, Wang et al. [27] reported that the ALBI grade more accurately predicts postoperative liver failure than the Child-Pugh grade. However, the Child-Pugh grade itself is a relatively rough grading system and was not intended for the prediction of liver failure after 


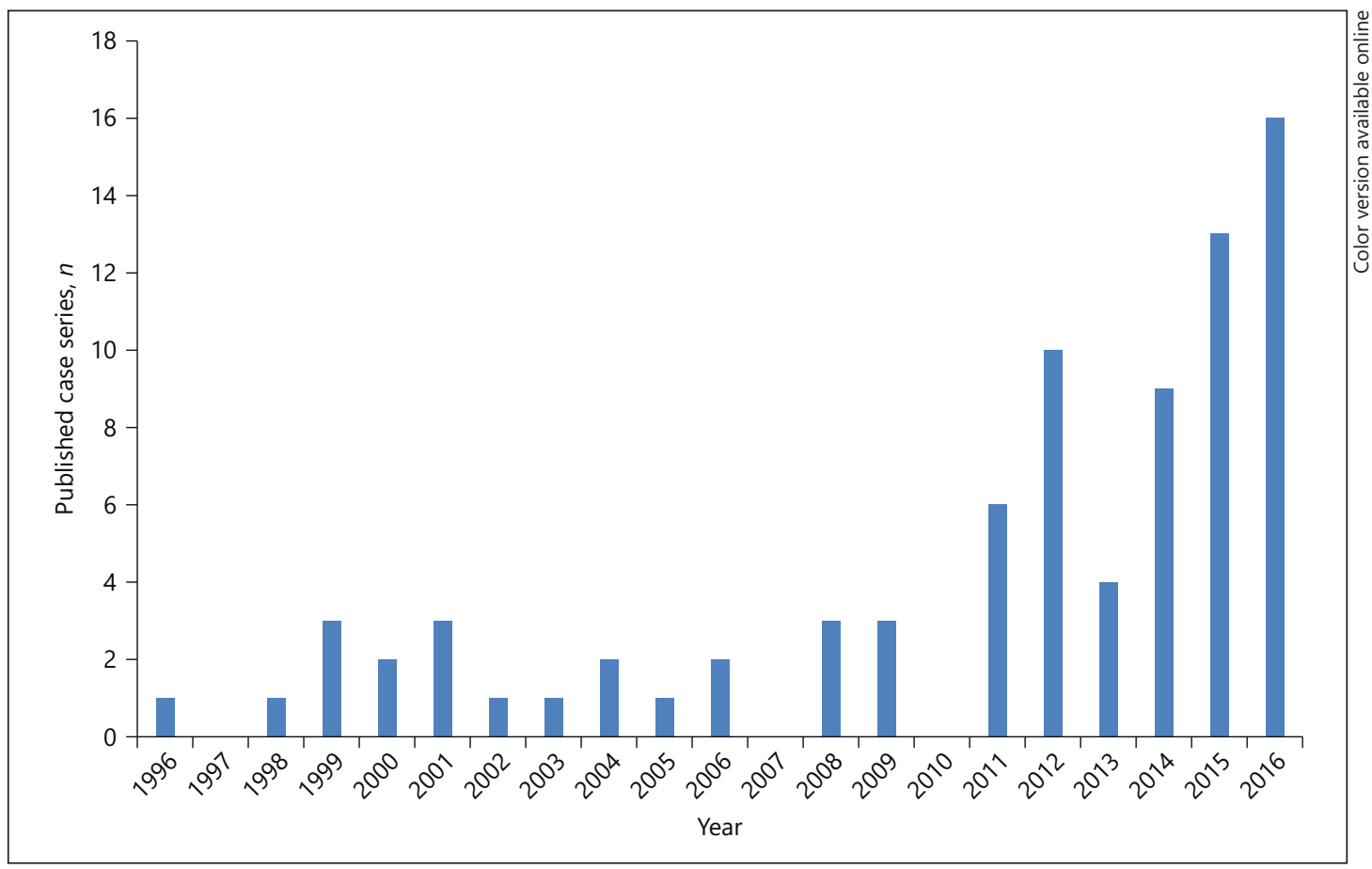

Fig. 1. Number of published case series concerning liver resection in hepatocellular carcinoma patients with portal hypertension.

hepatectomy. Although the ALBI grade could replace the Child-Pugh grade in preoperative liver function assessments, it is certainly not sufficient to decide a surgical strategy based only on the ALBI grade in the present era [14].

\section{Portal Hypertension}

The clinical impact of $\mathrm{PH}$ in postoperative clinical decompensation was first reported by Bruix et al. in 1996 [7]. The study included only 29 Child-Pugh A patients, and 23 of them (79\%) underwent an anatomical resection, which was considered to be a sectionectomy or major liver resection during the era of the report. Based on these findings, the AASLD/BCLC guideline listed $\mathrm{PH}$ as a contraindication for liver resection [4]. Clinically relevant $\mathrm{PH}$ is defined as a hepatic vein pressure gradient greater than $10 \mathrm{~mm} \mathrm{Hg}$ or the presence of esophageal varices or splenomegaly associated with a platelet count lower than $100 \times 10^{9} / \mathrm{L}$ [3]. Recently, the same group reported a systematic review and meta-analysis including 11 studies examining this issue [28]. The authors found that the PH increased the risk of 3- and 5-year mortality (pooled odds ratio [OR] for 3-year mortality: 2.09; 95\% confidence interval [CI]: 1.52-2.88; for 5-year mortality: 2.07 ; 95\% CI: 1.51-2.84) and the risk of postoperative clinical decompensation (pooled OR: 3.04; 95\% CI: 2.02-4.59). They concluded that although $\mathrm{PH}$ has to be considered a major negative prognostic factor, the presence of $\mathrm{PH}$ should not be regarded as an absolute contraindication for surgery [28].

The number of published case series concerning liver resection in HCC patients with PH since 1996 is shown in Figure 1. Original articles were searched through PubMed using the keywords "hepatocellular carcinoma" AND ["surgery" OR "hepatectomy" OR "resection"] AND "portal hypertension". Although the total number of the articles was 81, after the initial 


\section{Liver
Cancer}

\begin{tabular}{l|l}
\hline \multicolumn{2}{l}{ Liver Cancer 2019;8:447-456 } \\
\hline DOI: 10.1159/000501368 & $\begin{array}{l}\text { @ 2019 S. Karger AG, Basel } \\
\text { www.karger.com/lic }\end{array}$ \\
\hline
\end{tabular}

Kokudo et al.: Assessment of Preoperative Liver Function

Table 1. List of previous publications on the frequency of major liver resection and the mortality rate in patients with portal hypertension

\begin{tabular}{|c|c|c|c|c|c|c|}
\hline \multirow[t]{2}{*}{ Study, year (No. of subjects) } & \multicolumn{2}{|c|}{ Two or more segments } & \multicolumn{2}{|c|}{ 30-day mortality } & \multicolumn{2}{|c|}{ 90-day mortality } \\
\hline & $\mathrm{PH}$ & No PH & $\mathrm{PH}$ & No PH & $\mathrm{PH}$ & No PH \\
\hline Capussotti, $2006(n=217)$ [29] & $12(12 \%)^{*}$ & $39(33 \%)^{*}$ & \multicolumn{2}{|c|}{ na } & $11(11 \%)^{\S}$ & $6(5.1 \%)^{\S}$ \\
\hline Ishizawa, $2008(n=386)[30]$ & $3(2 \%)$ & $64(26 \%)$ & $1(0.7 \%)$ & $0(0 \%)$ & \multicolumn{2}{|c|}{ na } \\
\hline Ruzzenente, $2011(n=135)$ [31] & $8(18 \%)$ & $23(25 \%)$ & $2(4.6 \%)$ & $1(1.1 \%)$ & $6(14 \%)$ & $3(3.3 \%)$ \\
\hline Boleslawski, $2012(n=40)[32]$ & $4(22 \%)^{*}$ & $5(23 \%) *$ & $4(22 \%)$ & $1(4.5 \%)$ & $5(28 \%)$ & $1(4.5 \%)$ \\
\hline Santambrogio, $2013(n=223)$ [33] & $11(17 \%)$ & $50(31 \%)$ & $1(0.5 \%)$ & $0(0 \%)$ & $4(6 \%)$ & $3(2 \%)$ \\
\hline
\end{tabular}

* Three or more segments. ${ }^{\S} 60$-day mortality. PH, portal hypertension; na, not available.

report by Bruix et al. [7] in 1996, PH was considered to be a contraindication, and reports focusing on liver resection for patients with PH were scarce until 2010. Since 2011, however, the number of reports has increased, and recently there have been more than 10 reports annually. This result indicates that liver resection in HCC patients with PH is routinely performed in specialized centers worldwide.

Since $79 \%$ of patients underwent more than a sectionectomy in the initial report by Bruix et al. [7], we further focused on the mortality rate and the rate of major liver resection (Table 1). Five studies that reported the mortality rate and the extent of liver resection were identified. Capussotti et al. [29] initially reported the safety of liver resection for HCC patients with PH. In this study, the major liver resection rate (defined as three or more Couinaud's segments) was $12.1 \%(12 / 99)$ and the 60 -day mortality rate was $11.1 \%(11 / 99)$. Although the authors did not discuss the relationship between major liver resection and postoperative mortality in patients with $\mathrm{PH}$, the mortality rate and the major liver resection rate were quite similar. On the other hand, Ishizawa et al. [30] reported a mortality rate of $0.7 \%(1 / 136)$ after liver resection for HCC patients with $\mathrm{PH}$, which is quite low compared with other studies [28]. Of note, only $2 \%$ (3/136) of the patients underwent a resection of no less than one sector in this report. Ruzzenente et al. [31] reported a 3-month mortality rate of $13.6 \%(6 / 44)$ with $18.2 \%$ $(8 / 44)$ of the patients undergoing a resection larger than a segmentectomy. Boleslawski et al. [32] reported a prospective trial in which the hepatic venous pressure gradient was measured. In this study, the 90-day mortality rate was $27.8 \%$ (5/18), which was relatively high compared with those of other studies, along with a high major liver resection rate of $22.2 \%(4 / 18)$. In a report by Santambrogio et al. [33], 17.5\% (11/63) of patients with PH underwent a resection for 2 or more segments, with a 90-day mortality rate of $6.3 \%(4 / 63)$. One of the reasons for this relatively low mortality rate, compared with the major liver resection rate, may be the high rate of laparoscopic approach (41\%) in this study, as this procedure is significantly less invasive than open liver resection leading to less postoperative complications, such as ascites. Although the relationship between mortality and major resection in HCC patients with PH was not reported in these studies, the major liver resection rate and mortality rate were relatively well correlated (Table 1). These findings are consistent with recent results reported by Citterio et al. [34]. Through a single-center, retrospective study that included 543 HCC patients with chronic liver disease, the authors found that major liver resection in patients with $\mathrm{PH}$ was associated with a significant risk of postoperative liver decompensation (60\%) and liverrelated mortality $(25 \%)$.

Based on these results, the most recent European Association for the Study of the Liver (EASL) guidelines do not consider PH to be a contraindication for minor liver resection [35]. 


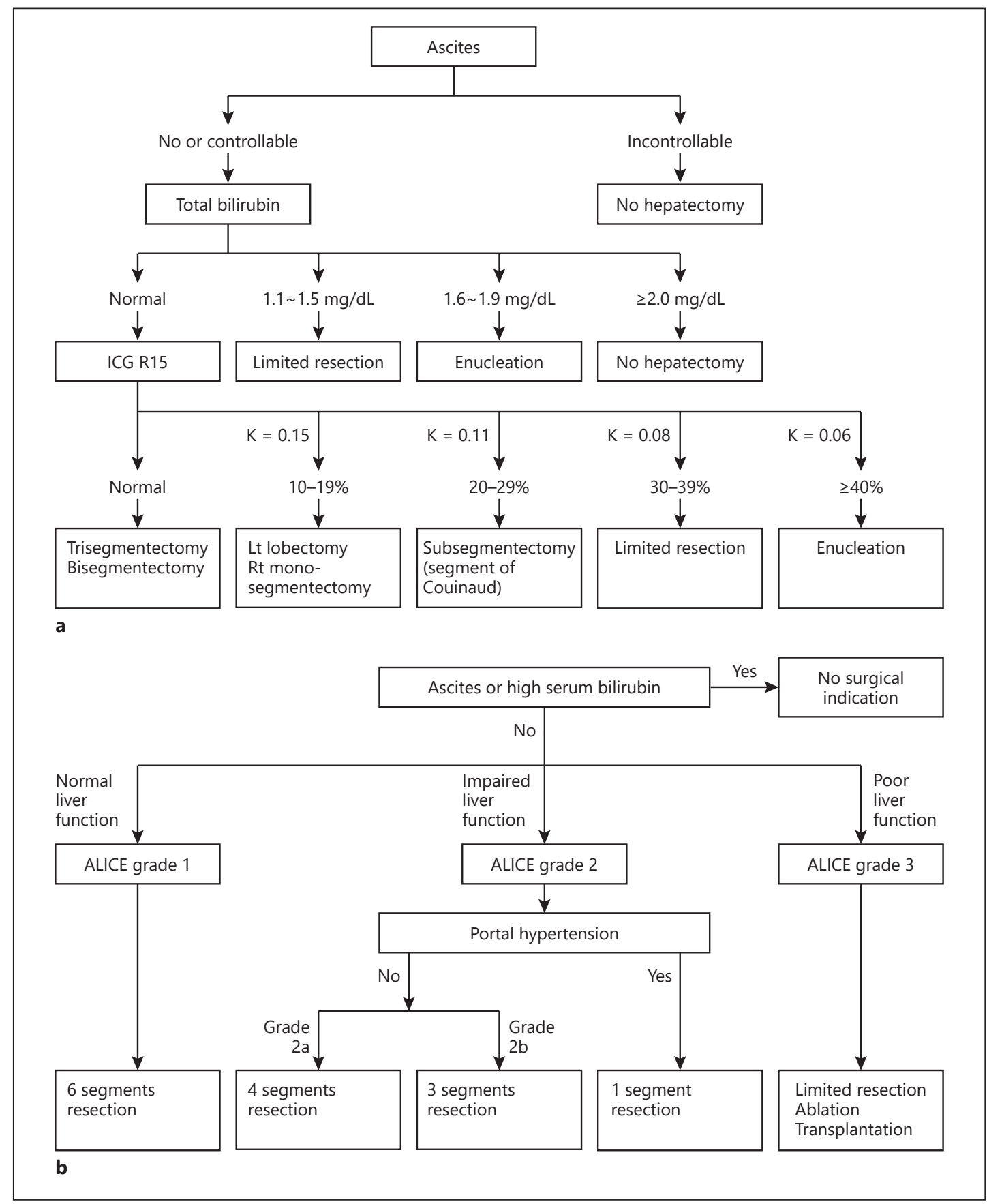

Fig. 2. a Makuuchi criteria for safe hepatic resection. (From Seyama et al. [1] with permission.) b Surgical decision making algorithm for safe hepatic resection based on albumin indocyanine green evaluation (ALICE) grade and portal hypertension. Portal hypertension is defined as presence of esophageal varices or splenomegaly associated with a platelet count lower than $100 \times 10^{9} /$ L. (From Shirata et al. [40] with permission.)

\section{Indocyanine Green Retention Rate}

A surgical decision making algorithm based on ICG R15 was first reported in the English literature by Makuuchi et al. in 1993 (Fig. 2a) [1, 8]. Since then, this algorithm has become widely used in Japan; nowadays, many Asian countries routinely use ICG R15 for preoperative 


\section{Liver Cancer}

\begin{tabular}{l|l}
\hline Liver Cancer 2019;8:447-456 \\
\hline DOI: 10.1159/000501368 & $\begin{array}{l}\text { O 2019 S. Karger AG, Basel } \\
\text { www.karger.com/lic }\end{array}$ \\
\hline
\end{tabular}

Kokudo et al.: Assessment of Preoperative Liver Function

liver function assessments, and the Japanese guidelines recommend the use of ICG R15 [5]. Although this algorithm has certainly contributed to a reduction in operative mortality in Japan [9], 3D volumetric analysis using contrast-enhanced computed tomography images to measure total liver volume (TLV), which excludes tumor and intrahepatic blood volume, was not routinely performed before liver resection when the algorithm was initially reported [20]. Therefore, the initial algorithm did not include the percentage of the remnant liver volume and the TLV ratio (RLV/TLV). Since portal vein embolization (PVE) is indicated for patients who are estimated to have an insufficient RLV/TLV, this parameter can be considered as a cut-off value. Kubota et al. [36] reported that PVE is indicated if the RLV/TLV is less than $40 \%$ in patients with normal liver and less than $50 \%$ in those with an ICG R15 value between 10-20\%. In the Western literature, Clavien et al. [37] proposed that an ICG R15 of less than $14 \%$ is the limit for major hepatectomy (RLV/TLV < $50 \%$ ) without PVE in patients with cirrhosis.

Recently Lisotti et al. [38] reported a prospective trial showing that the ICG R15 was correlated with $\mathrm{PH}$ and esophageal varices in patients with compensated liver cirrhosis. Similar to this result, in our previous study including 1,488 Child-Pugh A HCC patients, patients with PH had a significantly higher ICG R15 value than patients without clinically significant $\mathrm{PH}(17.7 \%$ vs. $12.3 \%, p<0.0001)$ [39]. Thus, the presence of $\mathrm{PH}$ is considered to reflect a poor ICG R15 value; however, the ICG R15 is a continuous, quantitative value and should be a more useful tool than PH for deciding the extent of major liver resection. Recently, we proposed a new model, based on long-term patient survival, called the Albumin-Indocyanine Green Evaluation (ALICE) grading system, as an evaluation tool to assess the preoperative liver functional reserve of patients undergoing hepatectomy for HCC. This score was calculated using the preoperative value of the serum albumin level and ICG R15 [39]. This new model assigned Child-Pugh A patients to ALICE grade $1(29 \%)$, grade $2(66 \%)$, and grade $3(5 \%)$ and Child-Pugh B patients to grade $1(1 \%)$, grade $2(61 \%)$, and grade $3(38 \%)$, respectively. This new system clearly stratified the postoperative risk in Child-Pugh A patients into three risk categories and was superior to $\mathrm{PH}$.

However, major liver resection and PH continue to be strong risk factors for postoperative liver failure, consistent with the results published by Citterio et al. [34]. Based on these results, we developed a new surgical decision-making algorithm based on the ALICE grade and $\mathrm{PH}$, as shown in Figure 2b [40]. Since the presence or absence of PH itself is not sufficiently useful to decide the extent of liver resection, a strategy that adds ICG R15 may represent a better and more effective set of criteria also for Western patients as well.

\section{Model for End-Stage Liver Disease (MELD) Score}

The MELD score was first reported to predict early death following an elective transjugular intrahepatic portosystemic shunt [41]. Now, it is widely used to decide whether liver transplantation is indicated. Several studies have suggested that the MELD score might be useful for predicting postoperative liver failure after hepatectomy for patients with HCC. Teh et al. [42] initially reported that a MELD score $\geq 9$ was a significant risk factor for postoperative mortality. Citterio et al. [34] reported that a combination of PH and MELD score was useful for predicting postoperative liver failure. Although the MELD score is a continuous variable and a cut-off value for liver resection could be selected independently, the original formula was developed for patients with extremely poor liver function in whom liver resection is not indicated [41]. Therefore, the usefulness of this scoring system for predicting postoperative liver failure might be limited. 


\section{Liver Cancer}

\begin{tabular}{l|l}
\hline Liver Cancer 2019;8:447-456 \\
\hline DOI: 10.1159/000501368 & $\begin{array}{l}\text { @ 2019 S. Karger AG, Basel } \\
\text { www.karger.com/lic }\end{array}$ \\
\hline
\end{tabular}

Kokudo et al.: Assessment of Preoperative Liver Function

\section{Other New Blood Chemistry Tests}

Other than the previously mentioned, widely used liver function assessment tools, Ichikawa et al. [43] reported a simple index using only the serum aspartate aminotransferase activity/ platelet count ratio that independently predicted hepatic failure following liver resection for HCC in a retrospective analysis of 366 patients. Another index in which age and alanine aminotransferase were added as parameters, the so-called Fibrosis index based on four factors (FIB-4), was reported to be a useful fibrosis marker for predicting postoperative liver failure in a singlecenter, retrospective study of 338 patients [44]. Donadon et al. [45] also reported a retrospective study of 336 patients and developed a very simple index involving only bilirubin and cholinesterases to identify patients who were potentially at risk for postoperative complications. The type IV collagen 7s domain, known to be a biochemical marker for assessing fibrosis in cirrhosis, was also reported to be correlated independently with hepatic failure following liver resection in a retrospective study of 251 HCC patients [46]. Mac-2 binding protein glycosylation isomer (M2BPGi) has recently become a well-known predictor for hepatic decompensation and HCC development in patients with chronic liver diseases, and it has also been reported to be useful for predicting postoperative liver failure in HCC patients [47]. All these liver function assessment tools can be easily measured using blood chemistry tests; however, the evidence is limited to relatively small, single-center, retrospective case series, and future validation is essential.

\section{Imaging Studies}

Other than blood chemistry tests, the use of clinical images such as elastography, scintigraphy, and magnetic resonance imaging has been reported. Elastography is now widely used as a noninvasive fibrosis assessment tool in place of liver biopsy. Indeed, in the Western literature, although the included numbers of patients have been relatively small, transient elastography measured using Fibroscan has been reported to be useful for predicting postoperative liver failure [48]. The predictive ability of liver single-photon emission computed tomography (SPECT) with technetium 99m-diethylenetriamine-pentaacetic acid-galactosyl human serum albumin (99mTc-GSA) has been extensively reported from Japan [49]. On the other hand, 99mTc-labeled mebrofenin hepatobiliary scintigraphy has been reported in the Western literature [50]. The superiority of these imaging studies is that they can be used to evaluate the liver function of the future remnant liver. Thus, they have been suggested to be useful in patients who have undergone PVE or associating liver partition and portal vein ligation (ALPPS) [50]. Similar to scintigraphy, enhancement with a hepatocyte-specific contrast agent (Gd-EOB-DTPA) has been reported to provide not only information on the liver tumor, but also combined anatomical and quantitative liver functional information. Recently, in a single-center, retrospective study of 115 patients, Chuang et al. [51] reported that the remnant contrast enhancement ratio measured using Gd-EOB-DPTA magnetic resonance imaging strongly predicted postoperative liver failure. Although accumulating evidence of the usefulness of imaging studies as liver function assessment tools have been reported, the results are still too controversial for these modalities to be recommended as routine examinations in clinical practice.

\section{Conclusions}

The present article overviewed the reported liver function assessment tools used for surgical decision making in patients with HCC. PH certainly has an impact and should be considered as a contraindication for major liver resection; however, it is not an absolute 
contraindication for minor liver resection. Future prospective studies focusing on volumetric analysis and liver function will be essential for the development of useful surgical decision making criteria in true clinical settings.

\section{Disclosure Statement}

The authors have no conflict of interest to declare.

\section{References}

1 Seyama Y, Kokudo N. Assessment of liver function for safe hepatic resection. Hepatol Res. 2009 Feb;39(2): 107-16.

2 Rahbari NN, Garden OJ, Padbury R, Brooke-Smith M, Crawford M, Adam R, et al. Posthepatectomy liver failure: a definition and grading by the International Study Group of Liver Surgery (ISGLS). Surgery. 2011 May; 149(5): 713-24.

3 Forner A, Llovet JM, Bruix J. Hepatocellular carcinoma. Lancet. 2012 Mar;379(9822):1245-55.

4 Bruix J, Reig M, Sherman M. Evidence-based diagnosis, staging, and treatment of patients with hepatocellular carcinoma. Gastroenterology. 2016 Apr;150(4):835-53.

5 Kokudo N, Hasegawa K, Akahane M, Igaki H, Izumi N, Ichida T, et al. Evidence-based Clinical Practice Guidelines for Hepatocellular Carcinoma: The Japan Society of Hepatology 2013 update (3rd JSH-HCC Guidelines). Hepatol Res. 2015 Jan;45(2):123-7.

6 Omata M, Cheng AL, Kokudo N, Kudo M, Lee JM, Jia J, et al. Asia-Pacific clinical practice guidelines on the management of hepatocellular carcinoma: a 2017 update. Hepatol Int. 2017 Jul;11(4):317-70.

7 Bruix J, Castells A, Bosch J, Feu F, Fuster J, Garcia-Pagan JC, et al. Surgical resection of hepatocellular carcinoma in cirrhotic patients: prognostic value of preoperative portal pressure. Gastroenterology. 1996 Oct;111(4): 1018-22.

8 Makuuchi M, Kosuge T, Takayama T, Yamazaki S, Kakazu T, Miyagawa S, et al. Surgery for small liver cancers. Semin Surg Oncol. 1993 Jul-Aug; 9(4):298-304.

9 Imamura H, Seyama Y, Kokudo N, Maema A, Sugawara Y, Sano K, et al. One thousand fifty-six hepatectomies without mortality in 8 years. Arch Surg. 2003 Nov;138(11):1198-206.

10 Dokmak S, Ftériche FS, Borscheid R, Cauchy F, Farges O, Belghiti J. 2012 Liver resections in the 21st century: we are far from zero mortality. HPB (Oxford). 2013 Nov;15(11):908-15.

11 Kenjo A, Miyata H, Gotoh M, Kitagawa Y, Shimada M, Baba H, et al. Risk stratification of 7,732 hepatectomy cases in 2011 from the National Clinical Database for Japan. J Am Coll Surg. 2014 Mar;218(3):412-22.

12 Zaydfudim VM, Kerwin MJ, Turrentine FE, Bauer TW, Adams RB, Stukenborg GJ. The impact of chronic liver disease on the risk assessment of ACS NSQIP morbidity and mortality after hepatic resection. Surgery. 2016 May;159(5):1308-15.

13 Kokudo T, Hasegawa K, Yamamoto S, Shindoh J, Takemura N, Aoki T, et al. Surgical treatment of hepatocellular carcinoma associated with hepatic vein tumor thrombosis. J Hepatol. 2014 Sep;61(3):583-8.

14 Mise Y, Hasegawa K, Shindoh J, Ishizawa T, Aoki T, Sakamoto Y, et al. The feasibility of third or more repeat hepatectomy for recurrent hepatocellular carcinoma. Ann Surg. 2015 Aug;262(2):347-57.

15 Pesi B, Ferrero A, Grazi GL, Cescon M, Russolillo N, Leo F, et al. Liver resection with thrombectomy as a treatment of hepatocellular carcinoma with major vascular invasion: results from a retrospective multicentric study. Am J Surg. 2015 Jul;210(1):35-44.

16 Kokudo T, Hasegawa K, Matsuyama Y, Takayama T, Izumi N, Kadoya M, et al.; Liver Cancer Study Group of Japan. Survival benefit of liver resection for hepatocellular carcinoma associated with portal vein invasion. J Hepatol. 2016 Nov;65(5):938-43.

17 Kokudo T, Hasegawa K, Matsuyama Y, Takayama T, Izumi N, Kadoya M, et al.; Liver Cancer Study Group of Japan. Liver resection for hepatocellular carcinoma associated with hepatic vein invasion: A Japanese nationwide survey. Hepatology. 2017 Aug;66(2):510-7.

18 Wigmore SJ, Redhead DN, Yan XJ, Casey J, Madhavan K, Dejong CH, et al. Virtual hepatic resection using threedimensional reconstruction of helical computed tomography angioportograms. Ann Surg. 2001 Feb;233(2): 221-6.

19 Kokudo T, Hasegawa K, Uldry E, Matsuyama Y, Kaneko J, Akamatsu N, et al. A new formula for calculating standard liver volume for living donor liver transplantation without using body weight. J Hepatol. 2015 Oct; 63(4):848-54.

20 Mise Y, Hasegawa K, Satou S, Shindoh J, Miki K, Akamatsu N, et al. How has virtual hepatectomy changed the practice of liver surgery?: experience of 1194 virtual hepatectomy before liver resection and living donor liver transplantation. Ann Surg. 2018 Jul;268(1):127-33. 
21 Child CG, Turcotte JG. Surgery and portal hypertension. Major Probl Clin Surg. 1964;1:1-85.

22 Pugh RN, Murray-Lyon IM, Dawson JL, Pietroni MC, Williams R. Transection of the oesophagus for bleeding oesophageal varices. Br J Surg. 1973 Aug;60(8):646-9.

23 Nakahara H, Itamoto T, Katayama K, Ohdan H, Hino H, Ochi M, et al. Indication of hepatectomy for cirrhotic patients with hepatocellular carcinoma classified as Child-Pugh class B. World J Surg. 2005 Jun;29(6):734-8.

24 Kuroda S, Tashiro H, Kobayashi T, Oshita A, Amano H, Ohdan H. Selection criteria for hepatectomy in patients with hepatocellular carcinoma classified as Child-Pugh class B. World J Surg. 2011 Apr;35(4):834-41.

25 Viganò L, Conci S, Cescon M, Fava C, Capelli P, D’Errico A, et al. Liver resection for hepatocellular carcinoma in patients with metabolic syndrome: A multicenter matched analysis with HCV-related HCC. J Hepatol. 2015 Jul; 63(1):93-101.

26 Johnson PJ, Berhane S, Kagebayashi C, Satomura S, Teng M, Reeves HL, et al. Assessment of liver function in patients with hepatocellular carcinoma: a new evidence-based approach-the ALBI grade. J Clin Oncol. 2015 Feb;33(6):550-8.

27 Wang YY, Zhong JH, Su ZY, Huang JF, Lu SD, Xiang BD, et al. Albumin-bilirubin versus Child-Pugh score as a predictor of outcome after liver resection for hepatocellular carcinoma. Br J Surg. 2016 May;103(6):725-34.

28 Berzigotti A, Reig M, Abraldes JG, Bosch J, Bruix J. Portal hypertension and the outcome of surgery for hepatocellular carcinoma in compensated cirrhosis: a systematic review and meta-analysis. Hepatology. 2015 Feb; 61(2):526-36.

29 Capussotti L, Ferrero A, Viganò L, Muratore A, Polastri R, Bouzari H. Portal hypertension: contraindication to liver surgery? World J Surg. 2006 Jun;30(6):992-9.

30 Ishizawa T, Hasegawa K, Aoki T, Takahashi M, Inoue Y, Sano K, et al. Neither multiple tumors nor portal hypertension are surgical contraindications for hepatocellular carcinoma. Gastroenterology. 2008 Jun; 134(7): 1908-16.

31 Ruzzenente A, Valdegamberi A, Campagnaro T, Conci S, Pachera S, Iacono C, et al. Hepatocellular carcinoma in cirrhotic patients with portal hypertension: is liver resection always contraindicated? World J Gastroenterol. 2011 Dec;17(46):5083-8.

32 Boleslawski E, Petrovai G, Truant S, Dharancy S, Duhamel A, Salleron J, et al. Hepatic venous pressure gradient in the assessment of portal hypertension before liver resection in patients with cirrhosis. Br J Surg. 2012 Jun; 99(6):855-63.

33 Santambrogio R, Kluger MD, Costa M, Belli A, Barabino M, Laurent A, et al. Hepatic resection for hepatocellular carcinoma in patients with Child-Pugh's A cirrhosis: is clinical evidence of portal hypertension a contraindication? HPB (Oxford). 2013 Jan;15(1):78-84.

34 Citterio D, Facciorusso A, Sposito C, Rota R, Bhoori S, Mazzaferro V. Hierarchic Interaction of Factors Associated With Liver Decompensation After Resection for Hepatocellular Carcinoma. JAMA Surg. 2016 Sep; 151(9):846-53.

35 Galle PR, Forner A, Llovet JM, Mazzaferro V, Piscaglia F, Raoul JL, et al.; European Association for the Study of the Liver. EASL Clinical Practice Guidelines: management of hepatocellular carcinoma. J Hepatol. 2018 Jul; 69(1):182-236.

36 Kubota K, Makuuchi M, Kusaka K, Kobayashi T, Miki K, Hasegawa K, et al. Measurement of liver volume and hepatic functional reserve as a guide to decision-making in resectional surgery for hepatic tumors. Hepatology. 1997 Nov;26(5):1176-81.

37 Clavien PA, Petrowsky H, DeOliveira ML, Graf R. Strategies for safer liver surgery and partial liver transplantation. N Engl J Med. 2007 Apr;356(15):1545-59.

38 Lisotti A, Azzaroli F, Buonfiglioli F, Montagnani M, Cecinato P, Turco L, et al. Indocyanine green retention test as a noninvasive marker of portal hypertension and esophageal varices in compensated liver cirrhosis. Hepatology. 2014 Feb;59(2):643-50.

39 Kokudo T, Hasegawa K, Amikura K, Uldry E, Shirata C, Yamaguchi T, et al. Assessment of Preoperative Liver Function in Patients with Hepatocellular Carcinoma - The Albumin-Indocyanine Green Evaluation (ALICE) Grade. PLoS One. 2016 Jul;11(7):e0159530.

40 Shirata C, Kokudo T, Arita J, Akamatsu N, Kaneko J, Sakamoto Y, et al. Albumin-Indocyanine Green Evaluation (ALICE) grade combined with portal hypertension to predict post-hepatectomy liver failure. Hepatol Res. 2019 Mar;hepr.13327.

41 Malinchoc M, Kamath PS, Gordon FD, Peine CJ, Rank J, ter Borg PC. A model to predict poor survival in patients undergoing transjugular intrahepatic portosystemic shunts. Hepatology. 2000 Apr;31(4):864-71.

42 Teh SH, Christein J, Donohue J, Que F, Kendrick M, Farnell M, et al. Hepatic resection of hepatocellular carcinoma in patients with cirrhosis: model of End-Stage Liver Disease (MELD) score predicts perioperative mortality. J Gastrointest Surg. 2005 Dec;9(9):1207-15.

43 Ichikawa T, Uenishi T, Takemura S, Oba K, Ogawa M, Kodai S, et al. A simple, noninvasively determined index predicting hepatic failure following liver resection for hepatocellular carcinoma. J Hepatobiliary Pancreat Surg. 2009;16(1):42-8.

44 Dong J, Zhang XF, Zhu Y, Ma F, Liu C, Wang WL, et al. The value of the combination of fibrosis index based on the four factors and future liver remnant volume ratios as a predictor on posthepatectomy outcomes. J Gastrointest Surg. 2015 Apr;19(4):682-91. 
45 Donadon M, Costa G, Cimino M, Procopio F, Fabbro DD, Palmisano A, et al. Safe hepatectomy selection criteria for hepatocellular carcinoma patients: a validation of 336 consecutive hepatectomies. The BILCHE score. World J Surg. 2015 Jan;39(1):237-43.

46 Kubo S, Tsukamoto T, Hirohashi K, Tanaka H, Shuto T, Takemura S, et al. Correlation between preoperative serum concentration of type IV collagen $7 \mathrm{~s}$ domain and hepatic failure following resection of hepatocellular carcinoma. Ann Surg. 2004 Feb;239(2):186-93.

47 Okuda Y, Taura K, Yoshino K, Ikeno Y, Nishio T, Yamamoto G, et al. Usefulness of Mac-2 Binding Protein Glycosylation Isomer for Prediction of Posthepatectomy Liver Failure in Patients With Hepatocellular Carcinoma. Ann Surg. 2017 Jun;265(6):1201-8.

48 Cescon M, Colecchia A, Cucchetti A, Peri E, Montrone L, Ercolani G, et al. Value of transient elastography measured with FibroScan in predicting the outcome of hepatic resection for hepatocellular carcinoma. Ann Surg. 2012 Nov;256(5):706-12.

49 Okabayashi T, Shima Y, Morita S, Shimada Y, Sumiyoshi T, Sui K, et al. Liver Function Assessment Using Technetium 99m-Galactosyl Single-Photon Emission Computed Tomography/CT Fusion Imaging: A Prospective Trial. J Am Coll Surg. 2017 Dec;225(6):789-97.

50 Olthof PB, Tomassini F, Huespe PE, Truant S, Pruvot FR, Troisi RI, et al. Hepatobiliary scintigraphy to evaluate liver function in associating liver partition and portal vein ligation for staged hepatectomy: liver volume overestimates liver function. Surgery. 2017 Oct;162(4):775-83.

51 Chuang YH, Ou HY, Lazo MZ, Chen CL, Chen MH, Weng CC, et al. Predicting post-hepatectomy liver failure by combined volumetric, functional MR image and laboratory analysis. Liver Int. 2018 May;38(5):868-74. 